\title{
Grit Ingestion and Size-related Consumption of Tubers by Graylag Geese
}

\author{
JUAN A. AMAT ${ }^{1,2}$ AND NICO VARO ${ }^{1}$ \\ ${ }^{1}$ Estación Biológica de Doñana, Consejo Superior de Investigaciones Científicas, \\ Apartado 1056, E-41080 Sevilla, Spain \\ 2Internet: amat@ebd.csic.es
}

\begin{abstract}
In herbivorous birds the processing rate of food is constrained by gizzard capacity. To enhance digestive processes, many species ingest grit to grind the food. Grit ingestion, however, may further limit the capacity of the gizzard. Graylag Geese (Anser anser) wintering in SW Spain fed mainly on Alkali Bulrush (Scirpus maritimus) tubers, showing a preference for small tubers. This preference may be due to a faster disintegration of small tubers than larger ones inside the gizzard. As larger tubers are likely coarser than smaller tubers, more grit would be necessary to process larger tubers. However, the ingestion of more grit to grind large tubers would be at the expense of ingesting additional tubers because of gizzard capacity limitations. Under these circumstances, there may be an inverse relationship between tuber size and amount of grit ingested to optimize food ingestion. Indeed, we found such a relationship. Grit facilitated the disintegration of tubers. This suggests that relying on some amount of grit to facilitate the grinding of food should outweigh the loss of gizzard capacity to the amount of food ingested.
\end{abstract}

Key words._-Anser anser, digestive bottleneck, Graylag Goose, grit ingestion, gizzard capacity, herbivorous birds.

Among the major functions that the muscular stomach, or gizzard, of birds performs, one is analog to that of the teeth of mammals, because it grinds the food into smaller particles to facilitate digestion (Ziswiler and Farner 1972). In herbivorous birds, the gizzard is highly specialized, possessing an inner keratinized cuticle that acts as a grinding apparatus during the contractions of the muscular stomach (Ziswiler and Farner 1972; Gill 1990). In spite of this specialization, herbivorous birds are not very efficient digesters of their food, so that they try to solve this problem by processing large quantities of food throughout the digestive tract. Although birds may have short food retention times (Dorozynska 1962; Burton et al. 1979; Prop and Vulink 1992), the processing rate is constrained by the capacity of the gizzard, so that foraging pauses are necessary to allow the digestive tract to be emptied (Kenward and Sibly 1977; Sibly 1981; Sedinger and Raveling 1988; Kersten and Visser 1996). To increase assimilation rates of food, many herbivorous birds ingest grit with which to enhance the action of the hard stomachal cuticle in grinding the food during contractions of the gizzard wall. By grinding the food, the more easily digestible components of the diet are probably easier to absorb, and also the transit time of food through the gizzard may be shortened because of the smaller size of finely ground food particles (Bjorndal et al. 1990; Prop et al. 2005). Indeed, although grit is not essential for digestion of plant material, without grit the digestive efficiency of herbivorous birds seems to be somewhat reduced (Ziswiler and Farner 1972; López-Calleja et al. 2000).

In many avian species there have been found positive correlations between the consumed amount of coarse food and the amount of grit ingested (Norman and Brown 1985; Gionfriddo and Best 1996, 1999; Best and Stafford 2002). In some bird species the amount of grit inside gizzards may represent between $1 / 2$ and $3 / 4$ of the volume of a full gizzard (Dawson et al. 1989; Gionfriddo and Best 1995, 1999). The ingestion of such large amounts of grit suggests that food processing rate may be further constrained by a reduction in gizzard capacity imposed by grit ingestion. This may imply that herbivorous birds must regulate the amount of grit ingested to avoid further limitations of the constraint of gizzard capacity on food processing rate.

North-western European continental populations of the Graylag Goose (Anser anser) winter mainly in the marshes of the Guad- 
alquivir in southwestern Spain (Bernis 1964; Nilsson et al. 1999), where they feed mainly on the tubers of Bulrush (Scirpus litoralis) and Alkali Bulrush (Scirpus maritimus) (Sánchez et al. 1977; Amat 1986a, 1995; Amat et al. 1991). This type of food is coarse and fibrous, and geese remove the roots from the tubers before ingesting them, thereby reducing the fibre content (Burton and Hudson 1978; Amat et al. 1991). Just after arriving at the marshes of the Guadalquivir in early autumn, Graylag Geese concentrate on Bulrush areas, but move onto Alkali Bulrush areas as soon as the latter areas become flooded after autumn rains (Amat 1986b). This habitat shift seems to be related to a preference for Alkali Bulrush tubers over those of Bulrush (Amat et al. 1991). In this wintering area, Alkali Bulrush tubers constitute, on a seasonal basis, a nonrenewable resource, because the growth of this plant starts in late winter, and the geese first consume the small Alkali Bulrush tubers leaving the larger ones for the late wintering season (Amat 1986a, 1995).

Because of the elliptic shape of Alkali Bulrush tubers, the gaps between tubers inside gizzards would increase with tuber size. As larger tubers are likely coarser than smaller tubers (see Discussion), more grit would be necessary to process larger tubers (Gionfriddo and Best 1996, 1999). Coarseness of food, however, limits the size into which particles may be broken down during digestive processes (Van Soest 1996), and to solve this problem herbivores may increase food intake rates (Owen 1972; Batzli and Cole 1979; Sibly 1981). Although grit could fit into the interstices between the tubers, the ingestion of more grit by Graylag Geese to grind large tubers would be at the expense of ingesting additional tubers because of gizzard capacity limitations. Under these circumstances, there may be an inverse relationship between tuber size and amount of grit ingested to optimize food ingestion. Accordingly, we predicted that, given the presumed inversed relationship between amount of grit ingested and food characteristics, there should be a seasonal variation in the amount of grit ingested by geese, related to the seasonal sizerelated consumption of Alkali Bulrush tu- bers. The aim of this paper was therefore at verifying this prediction.

\section{METHODS}

Graylag Geese wintering in the marshes of the Guadalquivir gathered at coastal dunes in which they obtained grit (sand) (Sánchez et al. 1977; Mateo et al. 2000). Geese were obtained from the bags of hunters in the marshes of the Guadalquivir during the hunting season of 19751976. The birds were usually shot in mid-morning when moving from feeding areas to resting sites. The gizzards were extracted and their contents stored in paper bags and dried. In the laboratory, grit was separated from the food by decantation and dried for $24 \mathrm{~h}$, after which the mass of grit was recorded with an electronic balance to the nearest $0.1 \mathrm{mg}$. All tubers found inside the gizzards examined were of Alkali Bulrush.

The total number of tubers found inside gizzards was estimated by counting the number of undamaged tubers as well as the number of partially disintegrated tubers. When possible, tubers found inside the gizzards were measured (maximum length to the nearest 0.1 $\mathrm{mm}$ ), recording also whether or not tubers were partially disintegrated. The size of tubers inside individual gizzards was averaged, distinguishing between partially disintegrated and non-disintegrated ones.

To examine whether there were differences in the volume of gaps between tubers of different sizes, tubers were re-hydrated for $24 \mathrm{~h}$, and small ( $\leq 8.0 \mathrm{~mm}$ long) and large ( $\geq 10.0 \mathrm{~mm}$ long) tubers (see Amat 1995) were selected. Tubers of each size category were placed filling $20 \mathrm{ml}$ in a 50:1/1 ml test tube, then water was added until all the gaps between the tubers were filled. Therefore, the volume of gaps between the tubers was equal to the volume of water added. Ten replicates of each treatment were made, in each one using different tubers.

\section{Statistical Analyses}

The relationship between the average size of tubers and the amount (by mass) of grit inside gizzards was examined using Pearson product-moment correlation. Differences in the amount of grit found inside geese gizzards in different periods were tested using analysis of variance (ANOVA). Differences in the volume of water necessary to fill gaps between tubers according to tuber size (large vs. small) were assessed with Student's independent t-test, and differences between the size of nondisintegrated tubers and that of partially disintegrated ones inside individual gizzards were assessed with Student's paired t-test. Finally, the relationship between the proportion of partially disintegrated tubers and the mass of grit in gizzards was examined, after controlling for the number of tubers inside gizzards, using partial correlation. The proportion of partially disintegrated tubers was arcsin-transformed before analysis to meet normality requirements. Mean values are presented \pm 1 SD, unless otherwise indicated.

\section{RESULTS}

Sand was found in all of 54 gizzards examined, with a mean mass of $10.8 \pm 5.6 \mathrm{~g}$ (range 28.3-0.8 g) per gizzard. As expected, 
there was an inverse relationship between the size of Alkali Bulrush tubers and the amount (by mass) of grit inside gizzards (Fig. $\left.1 ; \mathrm{r}_{48}=-0.30, \mathrm{P}=0.037\right)$. The size of tubers consumed by geese increased throughout the wintering season (data on the same individual geese presented in Amat 1995), but the amount of grit ingested showed a seasonal decline (Fig. 2; ANOVA, $\mathrm{F}_{2,51}=8.16, \mathrm{P}=$ $0.001)$. The volume of water necessary to fill gaps between tubers was greater when tubers were large $(10.7 \mathrm{ml} \pm 0.44)$ than when they were small $(9.3 \mathrm{ml} \pm 0.36)$ (Student's independent t-test, $\left.\mathrm{t}_{18}=8.19, \mathrm{P}<0.001\right)$.

Assuming that there were no size-related differences in the timing of ingestion of tubers in each feeding bout, the size of non-disintegrated tubers was larger $(9.8 \pm 1.97 \mathrm{~mm})$ than that of partially disintegrated ones (9.0 \pm 1.25 ) inside individual gizzards (Student's paired t-test, $\mathrm{t}_{49}=3.61, \mathrm{P}=0.001$ ). There was a significant relationship between the proportion of partially disintegrated tubers and the mass of grit in gizzards, after controlling for the number of tubers inside gizzards (partial $\mathrm{r}_{48}=0.28, \mathrm{P}=0.050$ ), indicating that grit aided in the mechanical grinding of food.

\section{DISCUSSION}

Most studies that have considered grit use by birds have analyzed the effects of different diet types on grit ingestion (Gionfriddo and Best 1996, 1999). However, the characteristics of a given type of food on grit in-

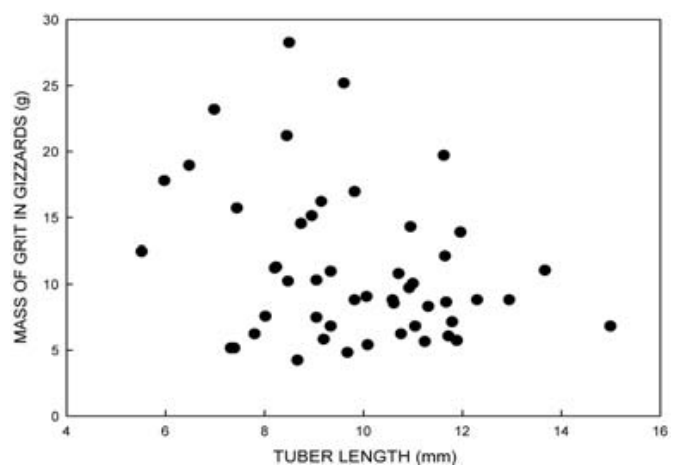

Figure 1. Relationship between the mass of grit and average tuber length in Graylag Geese gizzards.

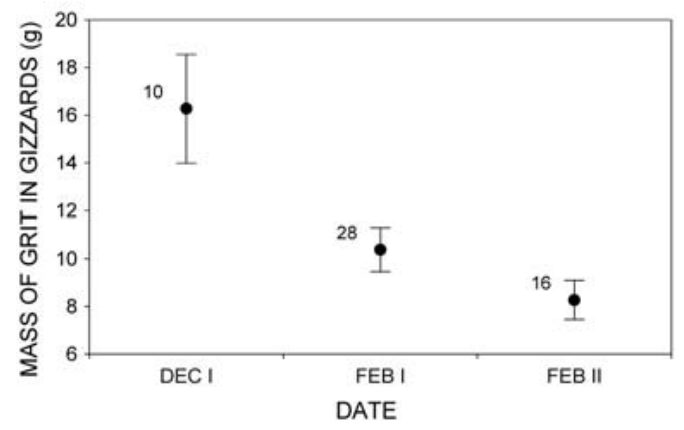

Figure 2. Mean mass of grit $\pm \mathrm{SE}$ in gizzards of Graylag Geese shot in the first half of December 1975 (Dec I), and the first (Feb I) and second (Feb II) halves of February 1976. Number of gizzards beside the points.

gestion patterns have not been considered previously. Although in this study there was an inverse relationship between the amount of grit in Graylag Goose gizzards and the size of tubers, the pattern observed was correlative and had a weak effect size. Given that larger tubers probably contain more fibre and, therefore, may be more difficult to break down, the results on grit ingestion by geese seem contrary to the pattern found in interspecific comparisons, in that large amounts of grit are often associated with diets consisting of coarse materials (Norman and Brown 1985; Gionfriddo and Best 1996). This apparent contradiction may be explained by considering the optimization of gizzard capacity. The gaps between tubers inside gizzards increased when the size of tubers increased, so that the apparent volume cost of these gaps might limit the amount of food ingested if such gaps were filled with grit (cf. Taylor 1993). One way to reduce these costs should be to ingest less grit as the size of tubers increases, so that more tubers could be ingested in each foraging bout. This suggests that geese have the ability to regulate their intake of grit (see also Halse 1983), so that they optimize the capacity of their gizzards.

It has been shown that the gizzard of birds is a rather plastic organ, as it may increase or decrease in size in a few days depending on food coarseness (Kehoe et al. 1988; Starck 1999; Dekinga et al. 2001; Figuerola et al. 2002; van Gilsl et al. 2003). By 
increasing the muscular mass of their gizzards, birds are able to crush the harder food items more easily (Guillemette 1998; van Gilsl et al. 2003). It is not known, however, whether after increasing the muscular mass of the gizzard, the capacity of the gizzard also increases. Nevertheless, the ingestion rates of hard food items may exceed the rate at which food items are defecated even during periods when birds have gizzards with a greater muscular mass (Guillemette 1998). This suggests that if there is a concurrent increase in gizzard capacity with increasing its muscular mass, such an increase is not enough to circumvent food processing constraints derived from a limitation of gizzard capacity. Given the importance of grit in facilitating digestion processes (see references above), the inverse relationship between tuber size and amount of grit suggests that if there is any increase in the size of Graylag Geese gizzards when the larger tubers are consumed, such an increase would not be enough to compensate for the loss of gizzard capacity derived from grit ingestion. It may be that birds trade-off muscle mass of the gizzard against grit ingestion when they consume coarse food items to optimize gizzard capacity.

Likely, the ingestion of grit facilitated the disintegration of tubers, as suggested by a relationship between the proportion of partially disintegrated tubers and the mass of grit inside gizzards, and perhaps relying on some amount of grit to enhance assimilation processes should outweigh the loss of gizzard capacity to the amount of food ingested. It should be interesting to show in future studies whether there is a grit ingestion-muscular mass of the gizzard interaction to optimize food processing rates.

\section{ACKNOWLEDGMENTS}

J. Castroviejo, M. Delibes and L. García collected the gizzards from hunters, and allowed us to examine their contents. Our field studies on geese were supported by Comisión Asesora de Investigación Científica y Técnica and Consejo Superior de Investigaciones Científicas. During manuscript preparation we were funded by $\mathrm{Di}$ rección General de Investigación with EU-ERDF support (research grant CGL2005-01136/BOS). Manuel Vázquez assisted in examining the contents of gizzards and sorting food and sand. Andy J. Green and an anonymous reviewer commented on previous drafts.

\section{LITERATURE CITED}

Amat, J. A. 1986a. Some aspects of the foraging ecology of a wintering Greylag Goose Anser anser population. Bird Study 33: 74-80.

Amat, J. A. 1986b. Numerical trends, habitat use and activity of Greylag Geese wintering in southwestern Spain. Wildfowl 37: 35-45.

Amat, J. A. 1995. Effects of wintering Greylag Geese Anser anser on their Scirpus food plants. Ecography 18: 155-163.

Amat, J. A., B. García-Criado and A. García-Ciudad. 1991. Food, feeding behaviour and nutritional ecology of wintering Greylag Geese Anser anser. Ardea 79: 271-282.

Batzli, G. O. and F. R. Cole. 1979. Nutritional ecology of microtine rodents: digestibility of forage. Journal of Mammalogy 60: 740-750.

Bernis, F. 1964. La invernada y migración de nuestros ánsares (Anser anser y Anser fabalis). Ardeola 9: 67-109.

Best, L. B. and T. R. Sttafford. 2002. Influence of daily grit consumption rate and diet on gizzard grit counts. Journal of Wildlife Management 66: 381-391.

Bjorndal, K. A., A. B. Bolten and J. E. Moore. 1990. Digestive fermentation in herbivores: effect of food particle size. Physiological Zoology 63: 710-721.

Burton, B. A. and R. J. Hudson. 1978. Activity budgets of Lesser Snow Geese wintering on the Fraser River Estuary, British Columbia. Wildfowl 29: 111-117.

Burton, B. A., R. J. Hudson and D. D. Bragg. 1979. Efficiency of utilization of bulrush rhizomes by Lesser Snow Geese. Journal of Wildlife Management 43: 728-735.

Dawson, T. J., A. B. Johns and A. M. Beal. 1989. Digestion in the Australian Wood Duck (Chenonetta jubata): a small avian herbivore showing selective digestion of the hemicellulose component of fiber. Physiological Zoology 62: 522-540.

Dekinga, A., M. W. Dietz, A. Koolhaas and T. Piersma. 2001. Time course and reversibility of changes in the gizzards of Red Knots alternately eating hard and soft food. Journal of Experimental Biology 204: 2167-2173.

Dorozynska, N. 1962. Food intake and defecation in the goose, Anser anser L. Acta Biologica Experimentalis 22: 227-240.

Figuerola, J., A. J. Green and L. Santamaría. 2002. Comparative dispersal effectiveness of wigeongrass seeds by waterfowl wintering in south-west Spain: quantitative and qualitative aspects. Journal of Ecology 90: 989-1001.

Gill, F. B. 1990. Ornithology. W. H. Freeman, New York. Gionfriddo, J. P. and L. B. Best. 1995. Grit use by House Sparrows: effects of diet and grit size. Condor 95: 57-67.

Gionfriddo, J. P. and L. B. Best. 1996. Grit-use patterns in North American birds: the influence of diet, body size and gender. Wilson Bulletin 108: 685-696.

Gionfriddo, J. P. and L. B. Best. 1999. Grit use by birds: a review. Pages 89-148 in Current Ornithology, Volume 15 (V. Nolan, Jr., E. D. Ketterson and C. F. Thompson, Eds.). Kluver Academic/Plenum Publishers, New York.

Guillemette, M. 1998. The effect of time and digestion constraints in common eiders while feeding and diving over blue mussel beds. Functional Ecology 12: 123-131.

Halse, S. A. 1983. Weight and particle size of grit in gizzards of Spur-winged Geese. Ostrich 54: 180-182. 
Kehoe, F. P., C. D. Ankney and R. T. Alisauskas. 1988. Effects of dietary fiber and diet diversity on digestive organs of captive Mallards (Anas platyrhynchos). Canadian Journal of Zoology 66: 1597-1602.

Kenward, R. E. and R. M. Sibly. 1977. A Woodpigeon (Columba palumbus) feeding preference explained by a digestive bottleneck. Journal of Applied Ecology 14: 815-826.

Kersten, M. and W. Visser. 1996. The rate of food processing in Oystercatcher: food intake and energy expenditure constrained by a digestive bottleneck. Functional Ecology 10: 440-448.

López-Calleja, M. V., M. Soto-Gamboa and E. L. Rezende. 2000. The role of gastrolites on feeding behavior and digestive efficiency in the Rufous-collared Sparrow. Condor 102: 465-469.

Mateo, R., A. Bonet, J. C. Dolz and R. Guitart. 2000. Lead shot densities in a site of grit ingestion for Greylag Geese Anser anser in Doñana (Spain). Ecotoxicology and Environmental Restoration 3: 76-80.

Nilsson, L., A. Follestad, K. Koffijberg, E. Kuijken, J. Madsen, J. Mooij, J. B. Mouronval, H. Persson, V. Schricke and B. Voslamber. 1999. Greylag Goose Anser anser: northwest Europe. Pages 182-201 in Goose Populations of the Western Palearctic: A Review of Status and Distribution (J. Madsen, G. Cracknell and T. Fox, Eds.). Publication No. 48, Wetlands International, Wageningen, The Netherlands.

Norman, F. I. and R. S. Brown. 1985. Gizzard grit in some Australian waterfowl. Wildfowl 36: 77-80.

Owen, M. 1972. Some factors affecting food intake and selection in White-fronted Geese. Journal of Animal Ecology 41: 79-92.

Prop, J. and T. Vulink. 1992. Digestion by Barnacle Geese in the annual cycle: the interplay between retention time and food quality. Functional Ecology 6: 180-189.

Prop, J., W. D. Van Marken Lichtenbelt, W. D. Beekman and J. F. Faber. 2005. Using food quality and retention time to predict digestion efficiency in geese. Wildlife Biology 11: 21-29.

Sánchez, A., J. Castroviejo and M. Delibes. 1977. On the wintering of Greylag Geese in the Marismas of the
Guadalquivir (southwestern Spain). Proceedings of the International Congress of Game Biologists 13: 65-76.

Sedinger, J. S. and D. G. Raveling. 1988. Foraging behavior of Cackling Canada Goslings: implications for the roles of food availability and processing rate. Oecologia 75: 119-124.

Sibly, R. M. 1981. Strategies of digestion and defecation. Pages 109-139 in Physiological Ecology: an Evolutionary Approach to Resource Use (C. R. Townsend and P. Calow, Eds.). Blackwell Scientific Publications, Oxford, UK.

Skead, D. M. and R. J. H. Mitchell. 1983. Grit ingested by waterfowl in relation to diet. South African Journal of Wildlife Research 13: 32-34.

Starck, J. M. 1999. Phenotypic flexibility of the avian gizzard: rapid, reversible and repeated changes of organ size in response to changes in dietary fibre content. Journal of Experimental Biology 202: 31713179.

Taylor, M. A. 1993. Stomach stones for feeding or buoyancy? The occurrence and function of gastroliths in marine tetrapods. Philosophical Transactions of the Royal Society of London B 341: 163-175.

Thomas, G. J., M. Owen and P. Richards. 1977. Grit in waterfowl at the Ouse Washes, England. Wildfowl 28: $136-138$.

Trost, R. E. 1981. Dynamics of grit selection and retention in captive Mallards. Journal of Wildlife Management 45: 64-73.

van Gilsl, J. A., T. Piersma, A. Dekinga and M. W. Dietz. 2003. Cost-benefit analysis of mollusc-eating in a shorebird II. Optimizing gizzard size in the face of seasonal demands. Journal of Experimental Biology 206: 3369-3380.

Van Soest, P. J. 1996. Allometry and ecology of feeding behavior and digestive capacity in herbivores: a review. Zoo Biology 15: 455-479.

Ziswiler, V. and D. S. Farner. 1972. Digestion and the digestive system. Pages 343-430 in Avian Biology, Volume II (D. S. Farner and J. R. King, Eds.). Academic Press, New York. 